\title{
RESEARCH
}

Open Access

\section{Vitamin D inhibits pro-inflammatory cytokines in the airways of cystic fibrosis patients infected by Pseudomonas aeruginosa- pilot study}

M. Olszowiec-Chlebna' , A. Koniarek-Maniecka ${ }^{1}$, A. Brzozowska' ${ }^{1}$ A. Błauż², B. Rychlik² and I. Stelmach ${ }^{1 *}$ (D)

\begin{abstract}
Background: Vitamin D plays an important role in inflammatory responses after antigen exposure. Interleukin-23 (II-23) promotes II-17-dependent inflammation during Pseudomonas aeruginosa (P. aeruginosa) pulmonary infection. We aimed to compare the ability of calcitriol and cholecalciferol to modulate the inflammatory response of the CF airways infected with $P$. aeruginosa.

Methods: This was a randomized, placebo-controlled, double-blind, cross-over trial. Twenty-three patients with CF (aged 6-19), chronically infected by $P$. aeruginosa were randomly assigned to: calcitriol group receiving $1,25(\mathrm{OH})_{2} \mathrm{D}$ 0,5 mcg daily or cholecalciferol group receiving cholecalciferol 1000 IU daily for three months. The levels of II-23 and II-17A in the exhaled breath concentrate (EBC) were measured. Calcium-phosphorus balance was also evaluated (serum concentration of calcium, phosphorus, 25OHD, parathormone (PTH) and calcium/creatinine ratio in urine). Data were analyzed using means of Stata/Special Edition, release 14.2. A level of $P<0.05$ was considered statistically significant.

Results: The level of II-17A in EBC significantly decreased in calcitriol group from 0,475 pg/mL ( \pm SD 0,515 pg/mL) to $0,384 \mathrm{pg} / \mathrm{mL}( \pm \mathrm{SD} 0,429 \mathrm{pg} / \mathrm{mL})(p=0,008)$; there was no change in cholecalciferol group $(p=0,074)$. The level of II-23 in EBC did not significantly change in calcitriol group $(p=0,086)$; there was significant decrease in cholecalciferol group from $8,90 \mathrm{pg} / \mathrm{mL}( \pm \mathrm{SD} 4,07 \mathrm{pg} / \mathrm{mL})$ to $7,33 \mathrm{pg} / \mathrm{mL}( \pm \mathrm{SD} 3,88 \mathrm{pg} / \mathrm{mL})(p=0,001)$. In calcitriol group serum phosphorus and PTH significantly decreased ( $p=0,021$ and $p=0,019$ respectively), the concentration of calcium significantly increased $(p=0,001)$; there were no changes in cholecalciferol group.

Conclusions: Both analogs of vitamin D revealed their anti-inflammatory effect and reduced the level of II-17A and II-23 in the airway of CF patients with chronic P. aeruginosa infection. We observed improvement in calciumphosphorus metabolism after supplementation with calcitriol, without adverse effects. It is recommended to use vitamin D in CF patients.
\end{abstract}

Keywords: Cystic fibrosis, Calcitriol, Cholecalciferol, Interleukin 17A, Interleukin 23

\footnotetext{
* Correspondence: alergol@kopernik.lodz.pl

${ }^{1}$ Department of Pediatrics and Allergy, Medical University of Lodz,

Copernicus Memorial Hospital, Korczak Paediatric Center, Piłsudskiego 71 Str,

90-329, Lodz, Poland

Full list of author information is available at the end of the article
}

(c) The Author(s). 2019 Open Access This article is distributed under the terms of the Creative Commons Attribution 4.0 International License (http://creativecommons.org/licenses/by/4.0/), which permits unrestricted use, distribution, and

reproduction in any medium, provided you give appropriate credit to the original author(s) and the source, provide a link to the Creative Commons license, and indicate if changes were made. The Creative Commons Public Domain Dedication waiver (http://creativecommons.org/publicdomain/zero/1.0/) applies to the data made available in this article, unless otherwise stated. 


\section{Background}

Cystic fibrosis (CF) is a chronic pulmonary disease that is associated with persistent microbial infection and chronic neutrophil infiltration. The major cause of morbidity and mortality is lung damage characterized by bronchiectasis. Chronic infection with Pseudomonas aeruginosa ( $P$. aeruginosa) is connected with a poor clinical outcome due to persistent inflammation and production of harmful products such as proteases and oxidants secreted mainly by neutrophils and also with elevated production of pro-inflammatory cytokines such as interleukin 17A (Il-17A) and interleukin 23 (Il-23) $[1,2]$. T helper 17 (Th17) cells produce Il-17A promoted by Il-23 and bind it to its receptor on the $\mathrm{T}$ cell membrane. They are both critical for neutrophil recruitment in a chronic $P$. aeruginosa pulmonary infection [3]. The role of the Il-17A/Il23 axis in pulmonary inflammation has been described in asthma, chronic obstructive pulmonary disease and in CF $[1,3-5]$. What is more its activation correlate with inflammation status in CF individuals $[1,3,5,6]$.

1,25-dihydroxycholecalciferol (calcitriol, $1,25(\mathrm{OH})_{2} \mathrm{D}$ ) is the hormonally active form of vitamin $\mathrm{D}$ essential for maintenance of bone and mineral homeostasis. It has been discovered to have many functions including immune system modulation [7-9]. $1,25(\mathrm{OH})_{2} \mathrm{D}$ has significant effects on function and signaling within $\mathrm{T}$ cell populations by downregulation monocyte toll like receptor (TLR) expression, trigger hypo-responsiveness to pathogen associated molecular patterns (PAMPs) and reduce co-stimulatory molecule and MHC II expression in monocytes and dendritic cells [9-12]. Consequently $1,25(\mathrm{OH})_{2} \mathrm{D}$ has been shown to mitigate the inflammatory effects of antigenic stimulation at epithelial surfaces $[10,11]$. Patients with $\mathrm{CF}$ are at particular risk for vitamin $\mathrm{D}$ deficiency due to the high prevalence of fat soluble vitamin malabsorption, impaired hydroxylation of vitamin D and reduced sun exposure [13, 14]. This may contribute to the exaggerated inflammatory response to pulmonary infection. Most patients with CF require oral supplementation to avoid vitamin $\mathrm{D}$ deficiency.

We compared the ability of calcitriol - an active form of vitamin D and cholecalciferol - obtained from supplements, to modulate the inflammatory response of the CF respiratory epithelium to pathogen challenge by analysis of changes in Il-17A and Il-23 concentration in the exhaled breath concentrate (EBC).

\section{Material and methods Subjects}

The total of 23 patients with CF including 11 women and 12 men between 6 and 19 years, attending the Cystic Fibrosis Outpatient Clinic in Copernicus Hospital in Lodz, Poland were included. Clinical and demographics characteristics of patients completing the study are shown in Table 1. Inclusion criteria were a diagnosis of $\mathrm{CF}$, age 6 years and older, forced expiratory volume in $1 \mathrm{~s}$ (FEV1) above 40\%, chronic $P$. aeruginosa infection (more than $50 \%$ of the monthly sputum samples positive for $P$. aeruginosa in the previous year). We excluded patients who had an exacerbation (defined by increase in symptoms, a deterioration of the FEV1 and documented radiological changes) and/or were on intravenous antibiotic therapy for at least 4 weeks before the study and/or patients with liver function abnormalities.

\section{Study design}

This was a randomized, placebo-controlled, double-blind, cross-over trial. The study was carried out from September 2015 to April 2016. There were four study visits. At all visits, spirometry and collection of EBC took place, also serum and urine samples were collected (Fig. 1). Informed consent was obtained from all subjects and their parents and the study was approved by the local ethical committee no RNN/21/14/KE.

Eligible subjects were randomized at the first visit and divided into 2 groups of patients:

- Eligible subjects were randomized at the first visit and divided into 2 groups of patients: calcitriol group receiving: $\mathbf{1 , 2 5}(\mathbf{O H})_{2} \mathbf{D} 0,5$ mcg daily in a capsule or cholecalciferol placebo in a capsule

or

- cholecalciferol group receiving: cholecalciferol 1000 IU daily in a capsule and calcitriol placebo in a capsule.

Randomization and treatment assignment were carried out by research pharmacy by standard allocation procedures. Only blind treatment codes were noted on randomization lists provided to study staff. All study staff and participants remained blind to treatment assignment.

Table 1 Baseline characteristics

\begin{tabular}{ll}
\hline Variables: & Characteristic: \\
\hline Age [years], mean \pm SD & $16,5 \pm 4,38$ \\
Male gender, $n(\%)$ & $12(52,7)$ \\
Mutation (CFTR) & \\
$\quad$ Delta F508/other, $n(\%)$ & $9(39,1)$ \\
$\quad$ Delta F508/Delta F508 $n(\%)$ & $10(43,4)$ \\
Others, $n(\%)$ & $4(17,3)$ \\
BMl $\left[\mathrm{kg} / \mathrm{m}^{2}\right]$ mean \pm SD & $16,4 \mathrm{~kg} / \mathrm{m}^{2} \pm \mathrm{SD} 13,43$ \\
FEV $1[\%$ best to predicted], mean $\pm \mathrm{SD}$ & $89,42 \pm 21,02$ \\
\hline
\end{tabular}




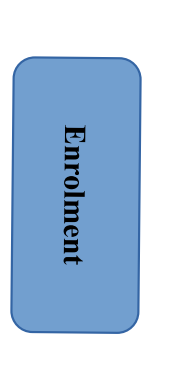

I. First visit: EBC, serum, urine, spirometry collection
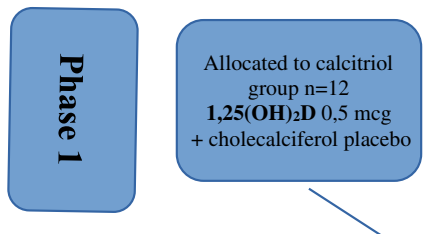

II. Second visit: EBC, sertm, urine, spirometry Collection

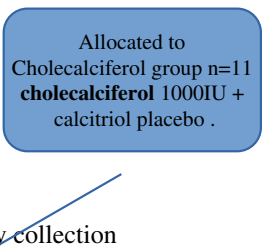

III. Third visit: EBC, serum, urine, spirometry collection
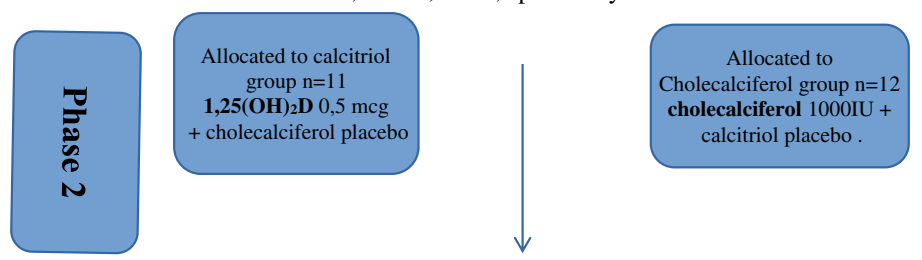

IV. Fourth visit: EBC, serum, urine, spirometry collection
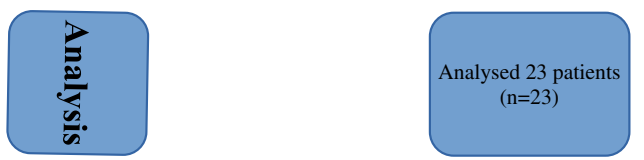

Fig. 1 Consort diagram

The participants received calcitriol (Rocaltrol, 0,5 mcg, Roche, caps.) 0,5 mcg per day or cholecalciferol - 1000 IU per day (Bioaron D 1000, $25 \mathrm{mcg}=1000 \mathrm{IU}$, Phytopharm, caps.) for three months. Calcitriol, cholecalciferol and placebo were blinded by the hospital pharmacy. Patients were informed that at this time, they cannot take other vitamin D supplements. Other CF treatment according to previous recommendation was maintained. After three months (the second visit) the patients for 4 weeks returned to their standard, recommended $\mathrm{CF}$ therapy (in which they did not take more than $800 \mathrm{IU}$ of cholecalciferol). At the third visit, according to their earlier randomization group, subjects received calcitriol $0,5 \mathrm{mcg}$ per day or cholecalciferol - $1000 \mathrm{IU}$ per day for the next three months. The fourth ending visit took place after 7 months from the first visit. Compliance with CF medication was checked; patients were asked to bring all used and unused medication to each follow-up visit.

\section{Lung function tests}

Pulmonary function testing was done with a Master Screen unit (Erich Jaeger Gmbh, Hochberg, Germany). During measurements, patients were instructed to sit upright, and a nose clip and a no compressible mouthpiece were used. All pulmonary function tests were performed according to the ATS/European Respiratory Society (ERS) standards [15]. The highest of the three successful measurements was taken and analyzed. The results were expressed as the percentage of a predicted value. 


\section{Collection and analysis of EBC}

The EBC was collected by using a commercially available condenser (EcoScreen; Jaeger) according to the current ATS/ERS guidelines. Samples of the EBC were obtained from subjects during tidal breathing while wearing a nose clip. The two-way non-rebreathing valves and tubing to the condenser served as a saliva trap. After a 10-min collection, the EBC was rapidly frozen in small plastic tubes at $80^{\circ} \mathrm{C}$ by using dry ice and was stored at $80^{\circ} \mathrm{C}$ until analysis. All EBC samples for biochemical markers of inflammation were measured by Laboratory of Cytometry, at Cathedral of Molecular Biophysics at the University of Lodz. The level of Il-23 was conducted by using separate competitive enzyme-linked immunosorbent assay kits ELISA (ELISA Quantikine, R\&D Systems) and Il-17A by using enhanced sensitivity cytometric bead array (BD ${ }^{\text {mi }}$ CBAray, Biosciences). All the assays were performed according to the manufacturer's instructions. Methods were based on literature research and the ability to quantify low concentrations of target analyzes in small volume samples.

\section{Laboratory tests}

In serum calcium-phosphorus balance was evaluated by assessment of concentration of calcium, phosphorus, 25OHD (by a specific radioimmunoassay 25-OH-vit.D3-RIA-CT, BioSource Europe S.A., Nivelles, Belgium), parathormone - PTH (by immunochemiluminescence assay -Intact PTH, Roche Diagnostic GmbH, Mannheim) and calcium/creatinine ratio in urine. All the above-mentioned measurements were made in the hospital laboratory using standard laboratory methods.

\section{Statistical analysis}

The investigated traits were described by way of measures of location - mean, along with measures of dispersion - standard deviation, 95\% confidence interval, and minimum-to-maximum values.

Mixed-effects regression models with robust standard errors were performed, considering both repeated measurements within the two separate studies and differences between the two studies. Intra-subject correlations also were incorporated into the mixed-effects regression models on grounds of the cross-over study design,. All the regression equations were controlled for the studied patients' age and gender.

A level of $P<0.05$ was considered statistically significant. All the statistical computations were carried out by means of Stata/Special Edition, release 14.2 (StataCorp LP, College Station, Texas, USA).

\section{Results}

There were no statistically significant differences in the baseline demographics of the study groups. Both cross-over study protocols comprised the total of 23 stable CF patients - Tables 1 and 2 All 23 subjects have completed the trial.

\section{Effect of calcitriol intake on II-17A level in EBC}

In the trial we study the effect of supplementation of 0,5 mcg of calcitriol on Il 17A and Il 23 level in EBC. At the end of tree months supplementation our results revealed lower level of Il-17A in EBC. It decreased from $0,475 \mathrm{pg} /$ $\mathrm{mL}( \pm \mathrm{SD} 0,515 \mathrm{pg} / \mathrm{mL})$ to $0,384 \mathrm{pg} / \mathrm{mL}( \pm \mathrm{SD} 0,429 \mathrm{pg} /$ $\mathrm{mL})(p=0,008)$. Respectively, we did not observe change in cholecalciferol group $(p=0,074)$. The difference between the two study groups was significant $(p=0,044)$ (Fig. 2).

\section{II-23 level in EBC decrease during supplementation with cholecalciferol}

To evaluate the immunomodulatory effect of vitamin D in this pilot study we determined the level of pro-inflammatory cytokine: Il-23 in EBC in stabile CF patients. As expected, the Il-23 level found in EBC decreases after supplementation with $1000 \mathrm{IU}$ of cholecalciferol from $8,90 \mathrm{pg} / \mathrm{mL}( \pm \mathrm{SD} 4,07 \mathrm{pg} / \mathrm{mL})$ to $7,33 \mathrm{pg} / \mathrm{mL}( \pm \mathrm{SD} 3,88 \mathrm{pg} / \mathrm{mL})$ after three months of treatment $(p=0,001)$ (Table 2, Fig. 3). Surprisingly, we did not observe changes of Il-23 level in calcitriol group.

\section{The effect of calcitriol and cholecalciferol supplementation on calcium-phosphorus balance}

The both group of patients receiving cholecalciferol and calcitriol did not increase their 25OHD serum level. It is probably connected with low dose of cholecalciferol. Whereas the calcitriol has no direct impact on 25OHD serum concentrations. However, in calcitriol group, levels of phosphorus and PTH significantly decreased ( $p=0,021$ and $p=0,019$ respectively) and the concentration of calcium significantly increased $(p=0,001)$ (Table 2). There was no change in the concentration of phosphorus, PTH and calcium after three months of treatment with cholecalciferol (Table 1). Urinary calcium/creatinine ratio did not change after three months of treatment in both study groups.

There were no significant changes in any of the studied clinical parameters in the both groups - BMI, FEV1.

\section{Discussion}

The role of the immunity in the pathophysiology of CF lung inflammation with a dominant neutrophilic type of inflammation has been established [16, 17]. Several investigators have demonstrated the ability of vitamin $\mathrm{D}$ to modulate the inflammatory response to antigen challenge at epithelial surfaces [7, 10-12]. In this study we showed that supplementation with vitamin $\mathrm{D}$ might have anti-inflammatory effect. We observed that 
Table 2 Descriptive statistics for analyzed measurable traits in the studied patients by study arm and phase of the study

\begin{tabular}{|c|c|c|c|c|c|c|c|c|}
\hline \multirow{3}{*}{$\begin{array}{l}\text { Analyzed trait } \\
\text { Age (years) }\end{array}$} & \multirow[t]{3}{*}{ Study arm } & \multirow{3}{*}{$\begin{array}{l}\text { Phase of } \\
\text { the study }\end{array}$} & \multicolumn{4}{|c|}{ Statistical parameter } & \multirow{2}{*}{\multicolumn{2}{|c|}{$\begin{array}{l}\text { Level of } \\
\text { statistical } \\
\text { significance } \\
(p \text {-value) }\end{array}$}} \\
\hline & & & \multirow{2}{*}{$\begin{array}{l}M^{a} \\
16,50\end{array}$} & \multirow{2}{*}{$\begin{array}{l}\mathrm{SD}^{\dagger} \\
4,38\end{array}$} & \multirow{2}{*}{$\begin{array}{l}95 \% \mathrm{Cl}^{\mathrm{b}} \\
14,32-18,68\end{array}$} & \multirow{2}{*}{$\begin{array}{l}\text { Min. - max. } \\
\frac{10-24}{}\end{array}$} & & \\
\hline & & & & & & & $a$ & $b$ \\
\hline \multirow[t]{4}{*}{ Phosphor (mmol/L) } & Calcitriol 0,5 mcg & Before treatment & 1,48 & 0,27 & $1,35-1,61$ & $1,03-1,93$ & $=0,021$ & $=0,359$ \\
\hline & & After treatment & 1,35 & 0,20 & $1,26-1,45$ & $1,04-1,70$ & & \\
\hline & Cholecalciferol $1000 \mathrm{IU}$ & Before treatment & 1,53 & 0,23 & $1,42-1,64$ & $1,05-1,87$ & $=0,080$ & \\
\hline & & After treatment & 1,44 & 0,18 & $1,35-1,54$ & $1,21-1,82$ & & \\
\hline \multirow[t]{4}{*}{ Calcium (mg/dL) } & Calcitriol 0,5 mcg & Before treatment & 3,50 & 2,60 & $2,28-4,72$ & $2,22-9,80$ & $=0,001$ & $=0,041$ \\
\hline & & After treatment & 4,35 & 3,35 & $2,78-5,92$ & $2,22-10,52$ & & \\
\hline & Cholecalciferol $1000 \mathrm{IU}$ & Before treatment & 2,81 & 1,62 & $2,03-3,59$ & $2,22-9,48$ & $=0,185$ & \\
\hline & & After treatment & 3,62 & 2,58 & $2,41-4,83$ & $2,15-9,80$ & & \\
\hline \multirow[t]{4}{*}{ Parathormone (pg/ml) } & Calcitriol 0,5 mcg & Before treatment & 35,64 & 17,61 & $27,40-43,88$ & $16,99-89,12$ & $=0,019$ & $=0,208$ \\
\hline & & After treatment & 29,36 & 13,08 & $23,23-35,48$ & $9,76-72,73$ & & \\
\hline & Cholecalciferol $1000 \mathrm{IU}$ & Before treatment & 38,30 & 13,62 & $31,92-44,67$ & $17,56-72,73$ & $=0,334$ & \\
\hline & & After treatment & 34,76 & 16,07 & $26,77-42,75$ & $17,07-89,12$ & & \\
\hline \multirow[t]{4}{*}{ Urinary calcium/creatinine ratio (mg/dL: mg/dL) } & Calcitriol 0,5 mcg & Before treatment & 0,262 & 0,195 & $0,168-0,356$ & $0,030-0,800$ & $=0,966$ & $=0,232$ \\
\hline & & After treatment & 0,239 & 0,201 & $0,143-0,336$ & $0,040-0,800$ & & \\
\hline & Cholecalciferol $1000 \mathrm{IU}$ & Before treatment & 0,252 & 0,138 & $0,188-0,317$ & $0,020-0,500$ & $=0,050$ & \\
\hline & & After treatment & 0,195 & 0,138 & $0,124-0,266$ & $0,020-0,500$ & & \\
\hline \multirow[t]{4}{*}{ 25-OH D (ng/mL) } & Calcitriol 0,5 mcg & Before treatment & 24,19 & 8,43 & $20,24-28,13$ & $5,20-40,00$ & $=0,125$ & $=0,064$ \\
\hline & & After treatment & 28,19 & 9,75 & $23,63-32,76$ & $8,10-42,90$ & & \\
\hline & Cholecalciferol $1000 \mathrm{IU}$ & Before treatment & 24,13 & 9,86 & $19,52-28,74$ & $9,40-48,30$ & $=0,567$ & \\
\hline & & After treatment & 24,97 & 10,86 & $19,89-30,06$ & $8,00-49,00$ & & \\
\hline \multirow[t]{4}{*}{ IL-17A in the exhaled air $(\mathrm{pg} / \mathrm{mL})$} & Calcitriol 0,5 mcg & Before treatment & 0,475 & 0,515 & $0,234-0,717$ & $0,050-1910$ & $=0,008$ & $=0,044$ \\
\hline & & After treatment & 0,384 & 0,429 & $0,184-0,585$ & $0,070-1800$ & & \\
\hline & Cholecalciferol $1000 \mathrm{IU}$ & Before treatment & 0,450 & 0,395 & $0,265-0,635$ & 0,050-1910 & $=0,074$ & \\
\hline & & After treatment & 0,290 & 0,195 & $0,199-0,382$ & $0,070-0,710$ & & \\
\hline \multirow[t]{4}{*}{ IL-23 in the exhaled air $(\mathrm{pg} / \mathrm{mL})$} & Calcitriol 0,5 mcg & Before treatment & 9,39 & 6,40 & $6,39-12,38$ & $2,12-30,72$ & $=0,086$ & $=0,399$ \\
\hline & & After treatment & 7,46 & 5,13 & $5,06-9,86$ & $1,03-20,37$ & & \\
\hline & Cholecalciferol $1000 \mathrm{IU}$ & Before treatment & 8,90 & 4,07 & $7,00-10,80$ & $3,04-20,72$ & $=0,001$ & \\
\hline & & After treatment & 7,33 & 3,88 & $5,51-9,15$ & $1,03-18,20$ & & \\
\hline
\end{tabular}

$\left({ }^{\mathrm{a}} \mathrm{M}\right.$ - mean, ${ }^{\dagger} \mathrm{SD}$ - standard deviation, ${ }^{\mathrm{b}} \mathrm{Cl}$ - confidence interval. Mixed-effects regression models with robust standard errors, due to the small sample size, were performed: a - considering repeated measurements in the two separate studies; $b$ - considering the above-mentioned repeated measurements, along with differences between the two studies and intra-subject correlation, on grounds of the cross-over study design. All statistical calculations were controlled for the studied patients' age and sex)

administering 0,5 mcg per day of calcitriol significantly reduced Il-17A in EBC and $1000 \mathrm{IU}$ per day of cholecalciferol reduced Il-23 in EBC in CF patients with chronic $P$. aeruginosa infection. Additionally, three months treatment with calcitriol improved calcium-phosphorus metabolism and had no adverse effects, whereas cholecalciferol in administered dose did not affect calcium-phosphorus balance.

Previous studies have shown that antigen presenting cells (APC) such as dendritic cells, that are activated by bacterial antigens in the bronchial mucus layer, produce Il-23 [4, 18]. and Il-17A [19, 20]. McAllister et al [21]. found elevated Il-23 and Il-17A protein levels in bronchoalveolar lavage (BAL) and sputum of CF patients during exacerbation and decreased levels after antibiotic therapy. Other study have shown elevated levels of Il-17A and Il-23 in sputum in clinically stable but chronically infected with $P$. aeruginosa CF patients [1]. Authors suggested that in these patients Il-17A/Il-23 axis has been stimulated via activation of toll like receptor (TLR). There is evidence that vitamin $\mathrm{D}$ can downregulate monocyte TLR expression, triggering hypo-responsiveness to pathogen associated molecular patterns (PAMPs) $[7,10,22]$. What is more, $1,25(\mathrm{OH})_{2} \mathrm{D}$ 


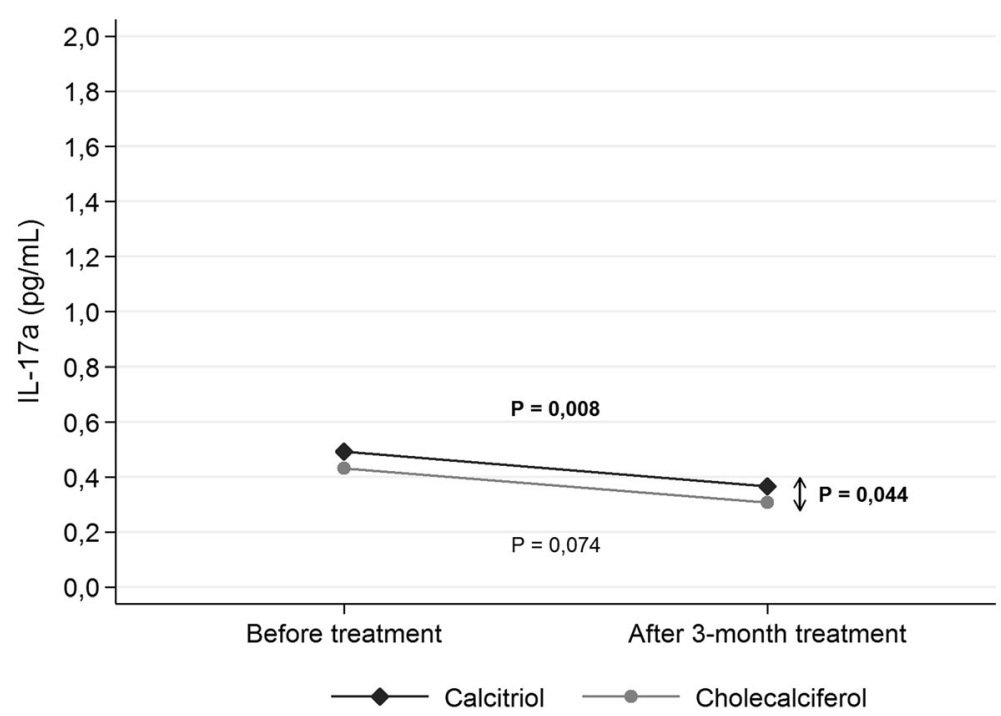

Fig. 2 Changes in the concentration of $11-17 \mathrm{~A}(\mathrm{pg} / \mathrm{mL})$ in the exhaled breath concentrate by the studied patients before and after 3-month treatment by study arm

upregulates expression and secretion of pro-inflammatory cytokines such as Il-1, Il-8 after challenge with Pseudomonas aeruginosa $[7,10]$. Our study demonstrated that either $1,25(\mathrm{OH})_{2} \mathrm{D}$ and cholecalciferol reduced Il-17A and Il-23 in EBC in CF patients with chronical infection with $P$. aeruginosa. However surprisingly, significant Il-17A reduction in EBC was gained in calcitriol group and significant decrease in Il-23 only in cholecalciferol group. We speculate that cholecalciferol and calcitriol both have immunomodulatory effects but they possibly affecting different pathways with different magnitude. What is more, calcitriol is the biologically active form of vitamin $\mathrm{D}$ and its effectiveness is independent of the functions of the organs, while cholecalciferol supplementation could be less efficient at some CF patients especially with impaired liver or kidney function. There is known that vitamin $\mathrm{D}$ can inhibit Il-17A/Il-23 axis via stimulation of TLR 4 or TLR 2. It is possible that calcitriol and cholecalciferol have different effect of pro-inflammatory cytokine via different TLR pathways what may result in a interleukin expression and different activation of dendritic cells [7, 9, 12]. Additionally 1,25(OH)2D3 increase cathelicidin expression - an antimicrobial which contribute to initial defence

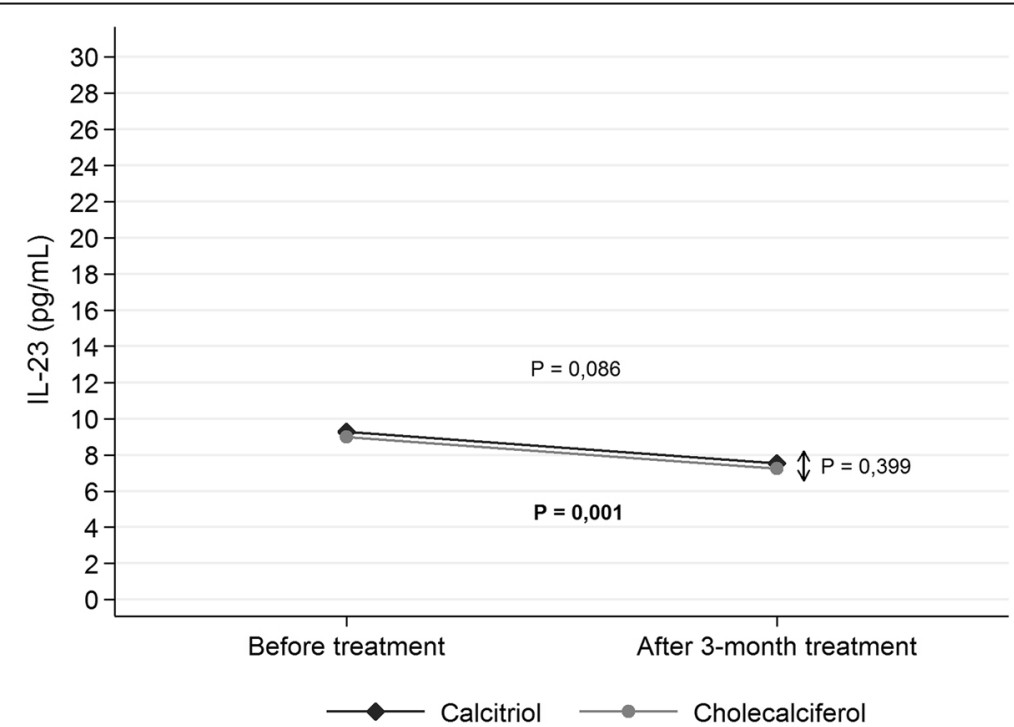

Fig. 3 Changes in the concentration of $11-23(\mathrm{pg} / \mathrm{mL})$ in the exhaled breath concentrate by the studied patients before and after 3-month treatment by study arm 
of the airway against inhaled pathogens [10,11]. Take both available literature and this study will not answer the question why that the statistically significant decrease of the two interleukins is found in two different treatment groups. Il-23 plays significant role in early, innate neutrophil recruitment and control Il-17 production by $\mathrm{T}$ cells [3]. Furthermore, Il-23 is considered as central mediator of the neutrophil inflammation seen in $P$. aeruginosa pulmonary infection. Some data have shown that neutralization of Il-23 did not result in worsening an infection $[1,3]$. The results suggested that $\mathrm{Il}-23$ is a promising target for the development of immunotherapeutic drugs that prevent morbidity and mortality in chronic $P$. aeruginosa pulmonary infection.

Due to calcitriol high potency, use of these vitamin $\mathrm{D}$ analog is associated with a higher risk of hypercalcemia and hypercalciuria compared to native vitamin D supplementation $[23,24]$. In this trail we observed improvement in calcium-phosphorus metabolism in our children without adverse effects. Many studies reported that calcitriol therapy has been hampered by the common occurrence of hypercalcemia, and a great risk of renal complications in addition to their higher cost.

In our study we used calcitriol as a final product of vitamin $\mathrm{D}$, which is intended for people with impaired liver and kidney function. The recommended calcitriol doses ranged from $0,25 \mathrm{mcg}$ to $1,0 \mathrm{mcg} /$ day as the most common dose [23, 24]. We administered the medium dose $0,5 \mathrm{mcg}$ per day of $1,25(\mathrm{OH})_{2} \mathrm{D}$ in calcitriol group.

Vitamin D and its hormonally active forms are essential for maintenance of bone and mineral homeostasis. Simultaneously it has been known that vitamin D has anti-inflammatory action [7-9]. Vitamin D insufficiency occurs frequently in CF patients due to the high prevalence of fat soluble vitamin malabsorption, impaired hydroxylation of vitamin $\mathrm{D}$ and reduced sun exposure $[13,14]$. This may contribute to the exaggerated inflammatory response to pulmonary infection. Most patients with CF require oral supplementation to avoid vitamin $\mathrm{D}$ deficiency but current vitamin $\mathrm{D}$ supplementation recommendations for $\mathrm{CF}$ were designed with a focus on bone health. The most trails which have shown reduction of inflammation and improved lung function in CF patient have administered at least a double dose (above $2000 \mathrm{IU}$ ) of cholecalciferol [25, 26]. Pincikova et al. [27]. randomized CF patients to receive 35,000-50,000 IU vitamin $\mathrm{D}$ per week for three months and observed that this supplementation has pleiotropic immunomodulatory effects in $\mathrm{CF}$ in a dose-dependent manner. Free serum $25 \mathrm{OH} \mathrm{D}$ level correlated positively with anti-inflammatory soluble immunological parameters, myeloid dendritic cells and $\mathrm{T}$ cell activation. We did not observe any statistically significant changes of 25OHD serum level due to the supplementation with cholecalciferol $1000 \mathrm{IU}$ per day. This is probably related to low dose of administered cholecalciferol what is the limitation of our study, as we were using earlier valid guidelines [28].

\section{Conclusions}

We demonstrated the ability of vitamin $\mathrm{D}$ to modulate the innate immunity and inflammatory response to antigen challenge in airway CF patients. Both analogs of vitamin D: cholecalciferol and calcitriol revealed their anti-inflammatory effect and reduced the level of Il-17A and Il-23 in EBC. Future research with vitamin D therapy is still needed and should focus on higher doses of vitamin $\mathrm{D}$ and using other active vitamin $\mathrm{D}$ analogs therapy on the inflammation status in CF patients.

\section{Abbreviations \\ 1,25(OH) 2 D: 1,25-dihydroxycholecalciferol (calcitriol); CF: Cystic fibrosis; EBC: Exhaled breath concentrate; II-17A: Interleukin 17A; II-23: Interleukin 23, P. aeruginosa: Pseudomonas aeruginosa; PTH: Parathormone \\ Acknowledgements \\ Not applicable. \\ Funding \\ The study was supported grant 503/2-056-01/503-01 from the Medical University of Lodz, Poland.}

\section{Availability of data and materials}

The datasets used and/or analysed during the current study are available from the corresponding author on reasonable request.

\section{Authors' contributions}

O-CM contributed to literature search, data collection, study design and manuscript preparation. K-MA contributed to literature search and data collection. BA contributed to literature search and data collection. BA contributed to assessment of cytokines. RB contributed to assessment of cytokines. SI contributed to literature search, analysis of data, study design and manuscript preparation. All authors read and approved the final manuscript.

\section{Ethics approval and consent to participate}

Informed consent was obtained from all subjects and their parents and the study was approved by the local ethical committee no RNN/21/14/KE.

\section{Consent for publication}

Not applicable.

\section{Competing interests}

The authors declare that they have no competing interests.

\section{Publisher's Note}

Springer Nature remains neutral with regard to jurisdictional claims in published maps and institutional affiliations.

\section{Author details}

${ }^{1}$ Department of Pediatrics and Allergy, Medical University of Lodz, Copernicus Memorial Hospital, Korczak Paediatric Center, Piłsudskiego 71 Str, 90-329, Lodz, Poland. 'Laboratory of Cytometry, Department of Molecular Biophysics, Faculty of Biology and Environmental Protection, University of Lodz, Lodz, Poland. 
Received: 16 January 2019 Accepted: 15 March 2019

Published online: 29 March 2019

\section{References}

1. Decraene A, Willems-Widyastuti A, Kasran A, De Boeck K, Bullens DM, Dupont LJ. Elevated expression of both mRNA and protein levels of IL-17A in sputum of stable cystic fibrosis patients. Respir Res. 2010;11(10):177.

2. Bullens DM, Decraene A, Seys S, Dupont LJ. IL-17A in human respiratory diseases: innate or adaptive immunity? Clinical implications. Clin Dev Immunol. 2013;2013:840315.

3. Dubin PJ, Martz A, Eisenstatt JR, Fox MD, Logar A, Kolls JK. Interleukin-23mediated inflammation in Pseudomonas aeruginosa pulmonary infection. Infect Immun. 2012;80(1):398-409.

4. Bullens DM, Truyen E, Coteur L, Dilissen E, Hellings PW, Dupont LJ. IL-17 mRNA in sputum of asthmatic patients: linking T cell driven inflammation and granulocytic influx? Respir Res. 2006;7:135.10.

5. Dubin PJ, McAllister F, Kolls JK. Is cystic fibrosis a TH17 disease? Inflamm Res. 2007;56:221-7.

6. McAllister F. Role of $\mathrm{IL}-17 \mathrm{~A}, \mathrm{IL}-17 \mathrm{~F}$, and the $\mathrm{IL}-17$ receptor in regulating growth-related oncogene-alpha and granulocyte colony- stimulating factor in bronchial epithelium: implications for airway in- flammation in cystic fibrosis. J Immunol. 2005:175:404-12.

7. McNally P, Coughlan C, Bergsson G, Doyle M, Taggart C, Adorini L, Uskokovic MR, et al. Vitamin D receptor agonists inhibit pro-inflammatory cytokine production from the respiratory epithelium in cystic fibrosis. J Cyst Fibros. 2011;10(6):428-34.

8. Grzelak T, Mikołajczyk K. Pleiotropic effect of vitamin D in cystic fibrosis. Adv Respir Med. 2018;(8):15.

9. Wani WA, Nazir M, Bhat Jl, Malik EU, Ahmad QI, Charoo BA, Ali SW. Vitamin D status correlates with the markers of cystic fibrosis-related pulmonary disease. Pediatr Neonatol. 2018;(7):19.

10. Yim S, Dhawan P, Ragunath C, Christakos S, Diamond G. Induction of cathelicidin in normal and CF bronchial epithelial cells by 1,25dihydroxyvitamin D(3). J Cyst Fibros. 2007;30(11):403-10.

11. Sadeghi K, Wessner B, Laggner U, Ploder M, Tamandl D, Friedl J. Vitamin D3 down-regulates monocyte TLR expression and triggers hyporesponsiveness to pathogen-associated molecular patterns. Eur J Immunol Feb. 2006;36(2):361-70.

12. Penna G, Adorini L. Alpha,25-dihydroxyvitamin D3 inhibits differentiation, maturation, activation, and survival of dendritic cells leading to impaired alloreactive T cell activation. J Immunol Mar. 2000;164(5):2405-11.

13. Moustaki M, Loukou I, Priftis KN, Douros K. Role of vitamin D in cystic fibrosis and non-cystic fibrosis bronchiectasis. World J Clin Pediatr. 2017;6(3):132-42.

14. Pincikova T, Paquin-Proulx D, Sandberg JK, Flodström-Tullberg M, Hjelte L. Clinical impact of vitamin D treatment in cystic fibrosis: a pilot randomized, controlled trial. Eur J Clin Nutr. 2017;71(2):203-5.

15. Miller MR, Hankinson J, Brusasco V. ATS/ERS task force. Standardisation of spirometry Eur Respir J. 2005;26:319-38.

16. Margaroli C, Garratt LW, Horati H, Dittrich AS, Rosenow T, Montgomery ST, Frey $\mathrm{DL}$, et al. Elastase exocytosis by airway neutrophils associates with early lung damage in cystic fibrosis children. Am J Respir Crit Care Med. 2018;(10):3.

17. Roesch EA, Nichols DP, Chmiel JF. Inflammation in cystic fibrosis: An update Pediatr Pulmonol. 2018;53(S3):S30-50.

18. Taylor PR, Bonfield TL, Chmiel JF, Pearlman E. Neutrophils from F508del cystic fibrosis patients produce IL-17A and express IL-23 - dependent IL17RC. Clin Immunol. 2016:170(9):53-60.

19. Hsu D, Taylor P, Fletcher D, van Heeckeren R, Eastman J, van Heeckeren A, Davis $\mathrm{P}$, et al. Interleukin-17 pathophysiology and therapeutic intervention in cystic fibrosis lung infection and inflammation. Infect Immun. 2016;84(9):2410-21.

20. Bayes HK, Ritchie ND, Evans TJ. Interleukin-17 is required for control of chronic lung infection caused by Pseudomonas aeruginosa. Infect Immun. 2018:84(12):3507-16

21. McAllister F, Henry A, Kreindler JL, Dubin PJ, Ulrich L, Steele C, et al. Role of IL-17A, IL-17F, and the IL-17 receptor in regulating growth-related oncogene-alpha and granulocyte colony-stimulating factor in bronchial epithelium: implications for airway inflammation in cystic fibrosis. J Immunol. 2005;175(1):404-12.
22. Ashenafi S, Mazurek J, Rehn A, Lemma B, Aderaye G, Bekele A, Assefa G, et al. Vitamin $D_{3}$ Status and the Association with Human Cathelicidin Expression in Patients with Different Clinical Forms of Active Tuberculosis. Nutrients 2018(6)4;10(6):721

23. Peppone LJ, Hebl S, Purnell JQ, Reid ME, Rosier RN, Mustian KM, Palesh OG, et al. The efficacy of calcitriol therapy in the management of bone loss and fractures: a qualitative review. Osteoporos Int. 2010;(7):1133-49.

24. Tanakol R, Gül N, Üzüm AK, Aral F. Calcitriol treatment in patients with low vitamin D levels. Arch Osteoporos 2018(10)23:13(1):114.

25. Simoneau T, Sawicki GS, Milliren CE, Feldman HA, Gordon CM. A randomized controlled trial of vitamin D replacement strategies in pediatric CF patients. J Cyst Fibros. 2016;15:234-41

26. Dauletbaev N, Herscovitch K, Das M, et al. Down-regulation of IL-8 by highdose vitamin $\mathrm{D}$ is specific to hyperinflammatory macrophages and involves mechanisms beyond up-regulation of DUSP1. Br J Pharmacol. 2015;172:4757-71.

27. Pincikova T, Paquin-Proulx D, Sandberg JK, Flodström-Tullberg M, Hjelte L. Vitamin D treatment modulates immune activation in cystic fibrosis. Clin Exp Immunol. 2017;189(3):359-71.

28. Walkowiak J, Pogorzelski A, Sands D, Skorupa W, Milanowski W, Nowakowska A, et al. Rules for the diagnosis and treatment of cystic fibrosis/Recommendations of the Polish Society of Cystic Fuibrosis 2009. Standardy Medyczne Pediatria. 2009(6):352-78.
Ready to submit your research? Choose BMC and benefit from:

- fast, convenient online submission

- thorough peer review by experienced researchers in your field

- rapid publication on acceptance

- support for research data, including large and complex data types

- gold Open Access which fosters wider collaboration and increased citations

- maximum visibility for your research: over $100 \mathrm{M}$ website views per year

At $\mathrm{BMC}$, research is always in progress.

Learn more biomedcentral.com/submissions 